\title{
Identifikasi sebaran awan konvektif menggunakan metode RGB dan CCO pada data satelit himawari-8 (studi kasus hujan lebat Putussibau 10 september 2020 )
}

\author{
Aditya Mulya \\ a Program Studi DIV Meteorologi, Sekolah Tinggi Meteorologi Klimatologi dan Geofisika, Jl Perhubungan I No. 5 \\ Komplek Meteo, Pondok Betung, Pondok Aren, Kota Tangerang Selatan, Banten, 15421, Indonesia. \\ aditya.mulya@stmkg.ac.id \\ *Correspondent Author
}

KAT AKUNCI

Fuzzy

Time Series

Prediksi

KEYWORDS

Fuzzy

Time Series

Forecasting
ABSTRAK

Putussibau merupakan daerah dengan pola curah hujan ekuatorial yang mempunyai dua puncak curah hujan tertinggi dalam satu tahun. Curah hujan yang tinggi disebabkan oleh adanya awan konvektif. Satelit Himawari-8 merupakan salah satu alat yang dapat mengidentifikasi sebaran awan konvektif. Pada tanggal 10 September 2020 terjadi hujan lebat di wilayah Putussibau dengan total curah hujan tercatat mencapai $78.6 \mathrm{~mm}$ dalam satu hari. Penelitian ini bertujuan untuk mengidentifikasi sebaran awan konvektif menggunakan metode Night Microphysics Red Green Blue (RGB-NM) dan Cloud Convective Overlays (CCO) pada data satelit Himawari-8. Metode RGB-NM menampilkan citra satelit sebaran awan menggunakan tiga komposit warna Red, Green dan Blue. Metode CCO merupakan teknik overlay awan dengan menggunakan dua algoritma yaitu Split Windows (SP=BTD[IR1-IR2]) dan Dual Channel Difference (S3=BTD[IR1-WV]). Hasil penelitian menunjukkan bahwa metode RGB-NM dan CCO mampu mengidentifikasi dengan baik sebaran awan konvektif yang menyebabkan terjadinya hujan lebat di Putussibau.

\section{Identification of convective cloud distribution using rgb and cco methods on himawari-8 satellite data (Putussibau heavy rain case study 10 september 2020}

Putussibau is an area with an equatorial rainfall pattern that has two of the highest rainfall peaks in one year. High rainfall is caused by convective clouds. The Himawari- 8 satellite is a tool that can identify the distribution of convective clouds. On September 10, 2020 there was heavy rain in the Putussibau area with a total rainfall of $78.6 \mathrm{~mm}$ in one day. This study aims to identify the distribution of convective clouds using the Night Microphysics Red Green Blue (RGB-NM) and Cloud Convective Overlays (CCO) methods on the Himawari-8 satellite data. The RGB-NM method displays satellite images of cloud distribution using three color composites of Red, Green and Blue. The CCO method is a cloud overlay technique using two algorithms, namely Split Windows (SP = BTD [IR1-IR2]) and Dual Channel Difference (S3 = BTD [IR1-WV]). The results showed that the RGB-NM and CCO methods were able to properly identify the distribution of convective clouds that caused heavy rain in Putussibau.

This is an open-access article under the CC-BY-SA license. 


\section{Pendahuluan}

Banjir merupakan bencana alam yang paling sering terjadi pada tahun 2020 dengan total kejadian 1.080[1]. Curah hujan yang tinggi merupakan salah satu faktor yang menyebabkan banjir dapat terjadi. Tingginya curah hujan umumnya disebabkan karena adanya awan konvektif. Awan Cumulonimbus (Cb) merupakan awan konvektif yang menghasilkan curah hujan yang tinggi dengan masa hidup 45 menit hingga beberapa jam. Awan $\mathrm{Cb}$ mudah diidentifikasi dari karakteristik fisiknya karena berbeda dari awan lainnya. Awab Cb berbentuk gundukan besar sedangkan pada bagian bawahnya lebih kecil dibandingkan dengan bagian atasnya [2][3].

Awan $\mathrm{Cb}$ dapat diamati secara langsung atau dengan menggunakan penginderaan jauh seperti Satelit Cuaca. Data Satelit Cuaca dapat digunakan untuk mengidentifikasi sebaran awan konvektif yang selanjutnya digunakan sebagai bahan pembuatan prakiraan cuaca [4][5]. Satelit Himawari-8 merupakan satelit Pusat Meteorologi Satelit Japan Meteorological Agency (JMA) yang mengorbit pada ketinggian $35.800 \mathrm{~km}$ di atas ekuator pada titik nadir $140,7^{\circ} \mathrm{BT}$ dan mengamati bumi dari $80^{\circ} \mathrm{BT}$ hingga $160^{\circ} \mathrm{BB}$ serta $60^{\circ} \mathrm{LU}$ hingga $60^{\circ} \mathrm{LS}$. Satelit Himawari-8 terdiri dari 16 kanal (Tabel 1 ) yang disertai dengan kemampuan pemindaian waktu yang cepat, yaitu 10 menit atau kurang sehingga mampu mengidentifikasi dan melacak fenomena awan konvektif yang berubah dengan cepat [6][7].

Tabel 1. Spesifikasi Satelit Himawari-8

\begin{tabular}{|c|c|c|c|}
\hline \multicolumn{4}{|c|}{ Himawari-8 } \\
\hline & Band & $\begin{array}{c}\text { Panjang } \\
\text { Gelombang } \\
(\mu \mathrm{m})\end{array}$ & $\begin{array}{c}\text { Resolusi } \\
\text { Spasial } \\
\text { (km) }\end{array}$ \\
\hline \multirow{3}{*}{ Visible } & 1 & 0.47 & \multirow{2}{*}{1} \\
\hline & 2 & 0.51 & \\
\hline & 3 & 0.65 & 0.5 \\
\hline \multirow{3}{*}{$\begin{array}{c}\text { Near- } \\
\text { infrared }\end{array}$} & 4 & 0.86 & \multirow[t]{6}{*}{1} \\
\hline & 5 & 1.6 & \\
\hline & 6 & 2.3 & \\
\hline \multirow{10}{*}{ Infrared } & 7 & 3.9 & \\
\hline & 8 & 6.2 & \\
\hline & 9 & 6.9 & \\
\hline & 10 & 7.3 & \multirow{7}{*}{2} \\
\hline & 11 & 8.6 & \\
\hline & 12 & 9.6 & \\
\hline & 13 & 10.4 & \\
\hline & 14 & 11.2 & \\
\hline & 15 & 12.4 & \\
\hline & 16 & 13.3 & \\
\hline
\end{tabular}

Salah satu metode dalam identifikasi awan konvektif dengan menggunakan satelit Himawari-8 adalah metode RGB. Metode RGB merupkan teknik untuk menampilkan warna menggunakan properti tiga warna primer cahaya ini (Merah, Hijau dan Biru) pada citra satelit. Metode RGB adalah metode yang direkomendasikan oleh World Meteorological Organization (WMO) dan banyak digunakan prakirawan dan peneliti meteorologi dunia [6][8]. Salah satu metode RGB yang baik untuk mendeteksi awan konvektif adalah Night Microphysics RGB (NMRGB) [9]. Metode NM-RGB merupakan skema khusus yang baik digunakan pada malam hari untuk mendeteksi awan tipis dan awan konvektif yang tebal. Skema RGB pada metode NM-RGB ditunjukkan pada Tabel 2 dan pada Tabel 3. 
Tabel 2. Komposisi band pada NM-RGB

\begin{tabular}{ccc}
\hline Color & Band & $\begin{array}{c}\text { Panjang } \\
\text { Gelombang } \\
(\boldsymbol{\mu} \boldsymbol{m})\end{array}$ \\
\hline Red & B13-B15 & $10.4-12.4$ \\
Green & B07-B13 & $3.9-10.4$ \\
Blue & B13 & 10.4 \\
\hline \multicolumn{3}{c}{ Sumber : Bessho [4] }
\end{tabular}

Tabel 3. Interpretasi warna pada NM-RGB

\begin{tabular}{c}
\hline Color \\
Interpretasi \\
Cery cold, thick, high-level cloud \\
Thin Cirrus cloud \\
Thick, mid-level cloud \\
Thin, mid-level cloud \\
Low-level cloud (cold atmosphere, \\
High latitude) \\
Low-level cloud (warm atmosphere, \\
low latitude) \\
Ocean \\
Land \\
\hline Sumber : Bessho[4]
\end{tabular}

Selain metode RGB, metode Convective Cloud Overlays (CCO) juga dapat digunakan untuk mengidentifikasi awan konvektif. Metode ini menggunakan perhitungan algoritma selisih antara beberapa kanal dan threshold yang sudah ditentukan pada Satelit Himawari-8. Metode ini mampu membedakan tutupan daerah awan konvektif dengan awan lainnya. Metode CCO Algoritma pertama menggunakan metode split windows dimana IR1-IR2 $\leq 2$, ini digunakan untuk membedakan antara awan konvektif dengan awan cirrus tipis. Algoritma kedua menggunakan Dual Channel Difference dimana IR1-IR3 $\leq 3$, ini digunakan untuk untuk membedakan antara awan konvektif dengan awan rendah [10][11].

Putussibau merupakan daerah dengan pola curah hujan ekuatorial yang mempunyai dua puncak curah hujan tertinggi dalam satu tahun. Pada tanggal 10 September 2020 terjadi hujan lebat di wilayah Putussibau dengan total curah hujan tercatat mencapai $78.6 \mathrm{~mm}$ dalam satu hari. Intensitas hujan ini merupakan kategori hujan lebat karena intensitasnya berada pada rentang 50-100 $\mathrm{mm} /$ hari menurut BMKG[12]. Sehingga penulis ingin mengidentifikasi sebaran awan konvektif dengan menggunakan metode RGB dan CCO yang mengakibatkan hujan lebat di wilayah Putussibau.

\section{Metode}

Metode yang digunakan dalam penelitian ini adalah metode kualitatif dengan menganalisis data citra satelit Himawari-8 yang diolah dengan menggunakan aplikasi GrADS dan SATAID. Secara umum alur penelitian ditunjukkan pada Gambar 1.

Langkah-langkah penelitian yang dilakukan antara lain :

1. Menentukan Lokasi penelitian

Penelitian ini dilakukan di wilayah Putussibau pada koordinat $00^{\circ} 50^{\prime} 08^{\prime \prime} \mathrm{LU}$ dan $112^{\circ} 56^{\prime} 09^{\prime \prime} \mathrm{BT}$.

2. Menentukan data dan periode penelitian

Data yang dikumpulkan adalah data Satelit Himawari-8 band 7, band 8, band 13, dan band 15 periode pukul 09.00UTC sampai dengan 12.30 UCT tanggal 10 September 2020. Periode ini ditentukan berdasarkan data pengamatan Stasiun Meteorologi 
Kapuas Hulu tercatat curah hujan sebesar $78.6 \mathrm{~mm}$ pada tanggal 10 September 2020. Data satelit Himawari-8 diperoleh dari Sub Bidang Pengelolaan Citra Satelit Cuaca BMKG.

3. Mengolah data satelit Himawari-8

Data satelit Himawari-8 pada periode yang sudah ditentukan diolah dengan menggunakan aplikasi SATAID untuk mengetahui time series dan countur awan konvektif. Metode NM-RGB digunakan untuk mengetahui sebaran awan konvektif menggunakan band 07, band 13, dan band 15 pada Satelit Himawari-8. Sedangkan aplikasi GrADS digunakan untuk mengetahui sebaran awan konvektif menggunakan metode CCO memanfaatkan band 08, band 13, dan band 15 pada Satelit Himawari8.

4. Menganalisis dan mengambil kesimpulan

Analisis dilakukan dengan melihat sebaran awan kovektif saat terjadi hujan lebat. Hasil pengolahan dengan menggunakan metode NM-RGB dan CCO dianalisis yang kemudian diambil kesimpulan berkaitan dengan sebaran awan konvektif di wilayah Putussibau 10 September 2020.

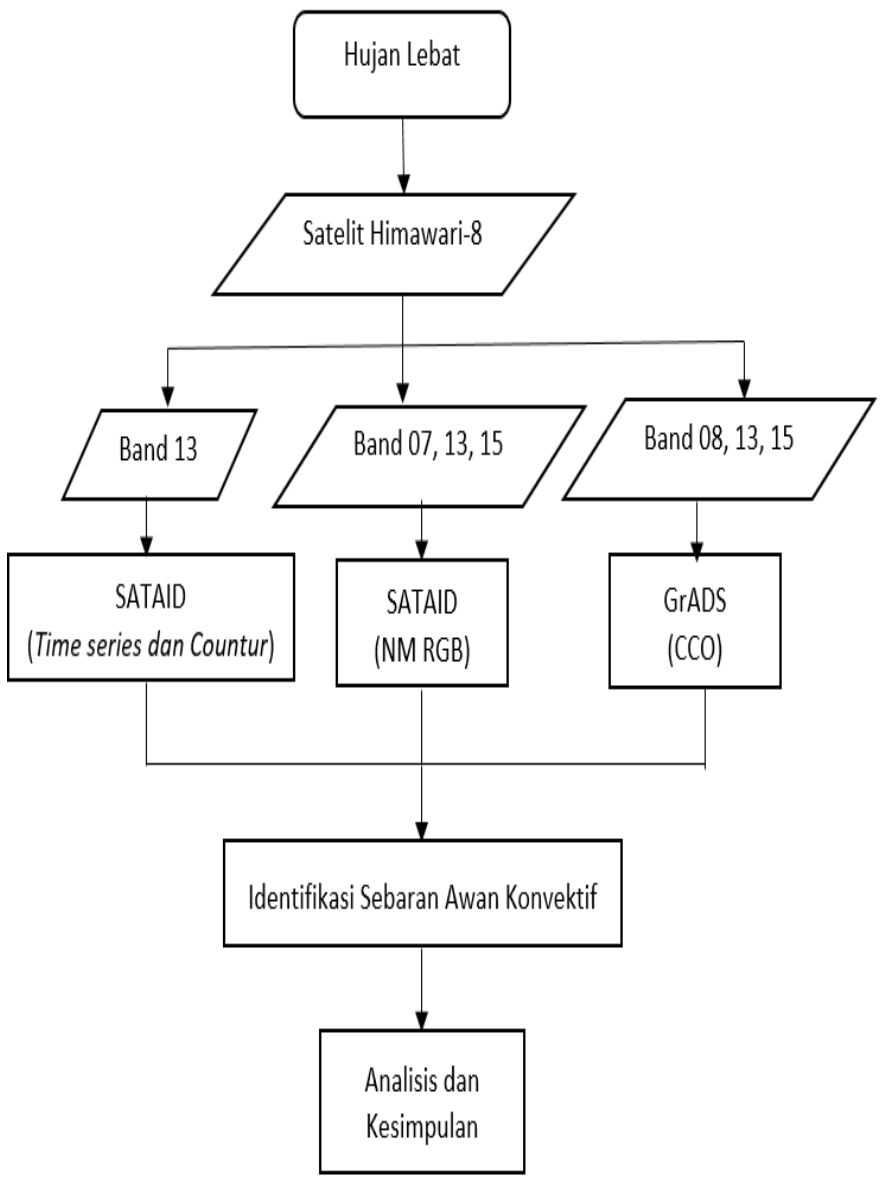

Gambar 1. Diagram Alir Penelitian

\section{Hasil dan Pembahasan}

\section{Analisis Time Series}

Hasil grafik time series suhu puncak awan awan (Gambar 2) berdasarkan band 13 (kanal inframerah) di Putussibau menunjukkan penurunan suhu puncak awan yang signifikan terjadi pada pukul 09.40 - 12.30 WIB. Penurunan suhu ini menunjukkan adanya arus updraft yang 
kuat sehingga menyebabkan pertumbuhan awan konvektif di wilayah tersebut. Berdasarkan suhu puncak awan dapat diidentifikasi tiga tahap pertumbuhan awan konventif. Tahap tumbuh terjadi pada pukul 09.40 - 10.40 UTC,tahap matang terjadi pada pukul 09.40 - 12.00 UTC, dan tahap punah terjadi pada pukul $12.00-12.30$ UTC. Awan konvektif pada fase matang memiliki suhu puncak awan paling rendah sebesar $67.5^{\circ} \mathrm{C}$. Kondisi inilah yang menyebabkan terjadinya hujan lebat di wilayah Putussibau.

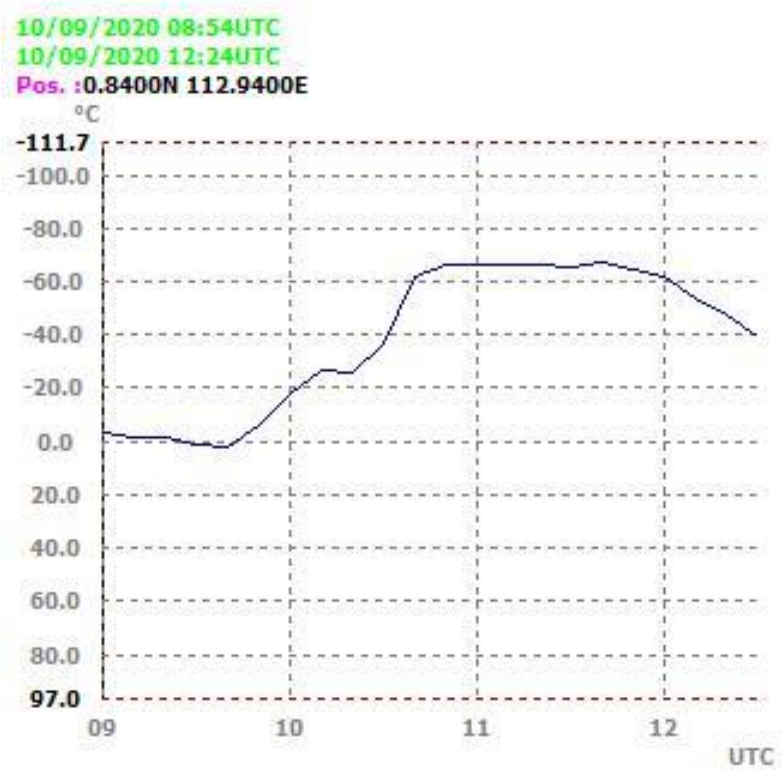

Gambar 2. Grafik Time series Suhu Puncak awan di Putussibau 10 September 2020

\section{Analisis Contour}

Hasil Contour suhu puncak awan konvektif menunjukkan wilayah penelitian memiliki suhu puncak awan yang lebih rendah di bandingkan wilayah lainnya [13]. Pada Gambar 3 suhu puncak awan di lokasi penelitian mencapai $67.5^{\circ} \mathrm{C}$. Sedangkan suhu puncak awan di sekitar lokasi penelitian hanya berkisar antara $2.5^{\circ} \mathrm{C}-7.5^{\circ} \mathrm{C}$. Kondisi wilayah yang memiliki suhu puncak awan yang semakin rendah menunjukkan bahwa diwilayah tersebut kondisi atmosfernya labil. Kondisi atmosfer yang labil ini memudahkan dalam pertumbuhan awan awan konvektif yang dapat menimbulkan hujan lebat di wilayah Putussibau.

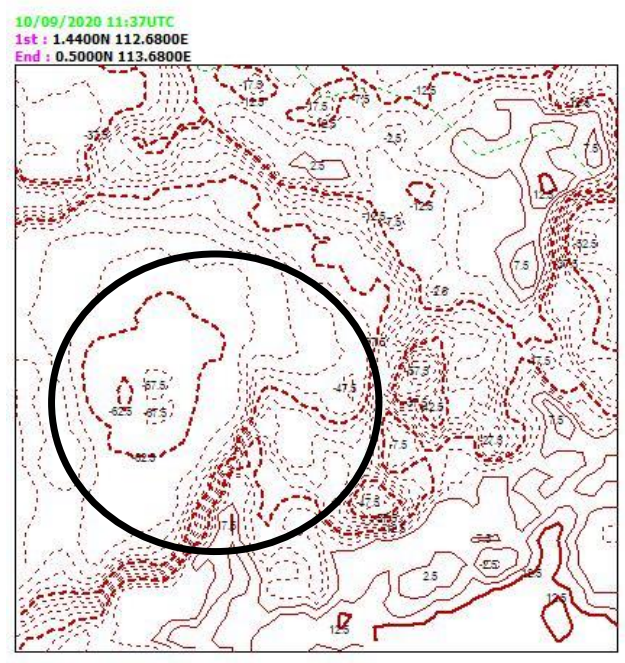

Gambar 3. Contour Suhu Puncak Awan di Putussibau 10 September 2020 pukul 11.30 UTC 


\section{Analisis Metode NM-RGB}

Hasil pengolahan dengan metode NM-RGB menunjukkan bahwa sebaran awan konvektif dapat diidentifikasi dengan baik. Warna merah menunjukkan bahwa awan tersebut sangat dingin, tebal dan berada pada ketinggian awan tinggi menurut Bessho, dkk [6][14]. Kondisi ini menunjukkan bahwa awan tersebut merupakan awan konvektif. Pada Gambar 4.a sebaran awan konvektif mulai terdapat atas wilayah Putussibau. Awan konvektif masih belum terdapat di wilayah penelitian akan tetapi sudah mulai tumbuh dan berkembang di sekitar wilayah penelitian. Gambar 4.b menunjukkan bahwa sebaran awan konvektif mulai bergerak menuju ke wilayah Putussibau. Sebaran awan konvektif sudah berada di wilayah penelitian seperti terlihat pada Gambar 4.c.

Sebaran awan konvektif mulai bergerak menjauhi wilayah penelitian dan bergerak ke arah Barat. Hasil penelitian ini selaras dengan penelitian Bessho, dkk [6] dimana metode NMRGB mampu untuk mengidentifikasi sebaran awan konvektif dengan baik pada saat malam hari. Awan konvektif inilah yang menyebabkan terjadinya hujan lebat di wilayah Putussibau.
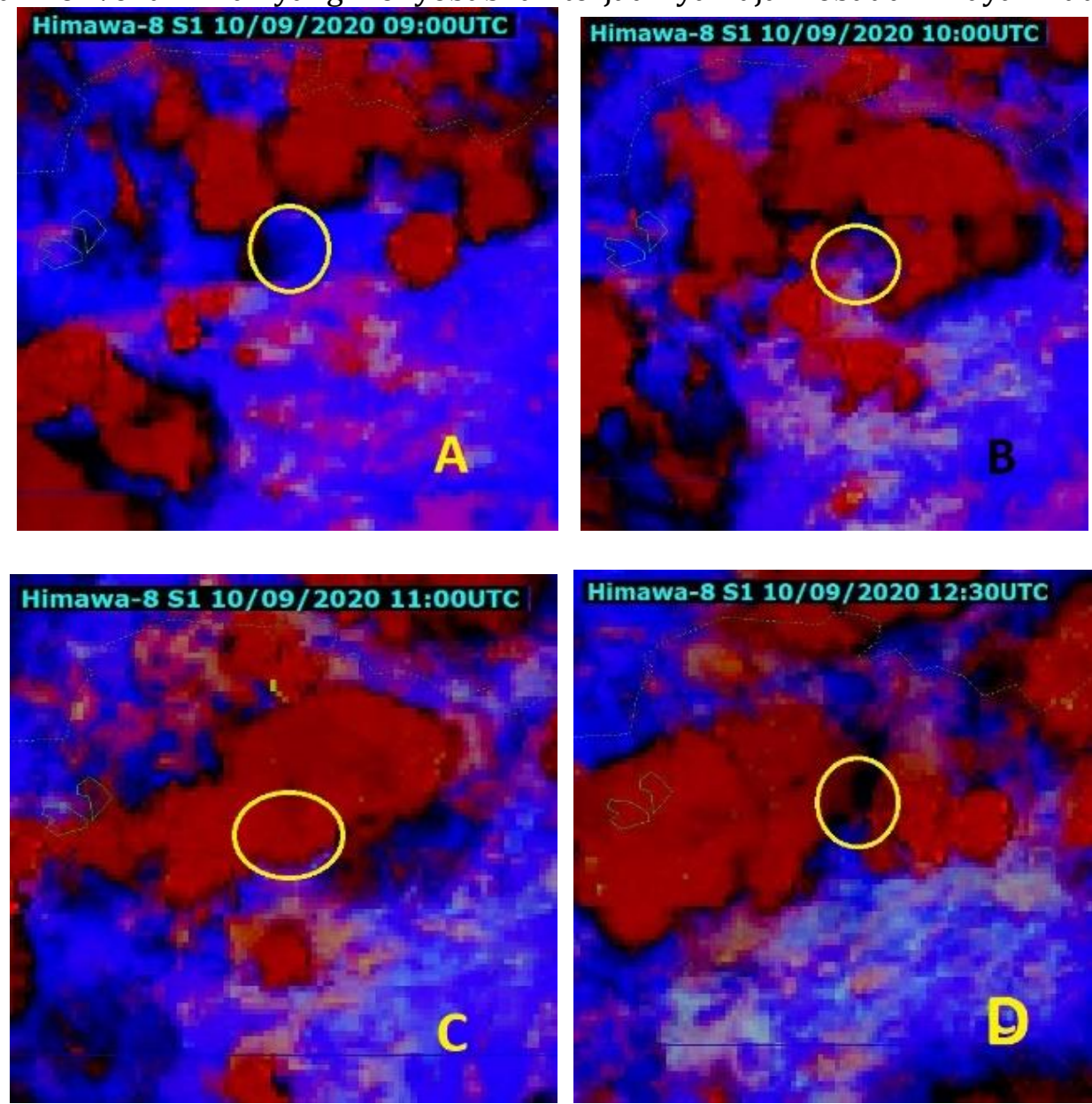

Gambar 4. Sebaran Awan Konvektif pukul 09.00 UTC (a), 10.00 UTC (b), 11.00 UTC (c) dan 12.30 UTC (d) di wilayah Putussibau menggunakan metode NM-RGB

\section{Analisis Metode CCO}

Hasil pengolahan dengan metode CCO mengidentifikasi sebaran awan konvektif dengan cukup baik. Hal ini terlihat seperti pada Gambar 5.a sebaran awan konvektif masih berada diatas wilayah penelitian. Pada Gambar 5.b sebaran awan konvektif mulai terlihat bergerak menuju ke wilayah penelitian. Gambar 4.c menunjukkan sebaran awan konvektif berada di wilayah penelitian. Sebaran awan konvektif mulai bergerak menjauhi wilayah penelitian dan bergerak ke arah Barat seperti terlihat pada Gambar 5.d. Hasil metode CCO pada penelitian ini 
juga selaras dengan penelitian Hastuti dan Mulsandi[15], dimana metode CCO mampu mengidentifikasi sebaran awan konvektif dengan cukup baik.
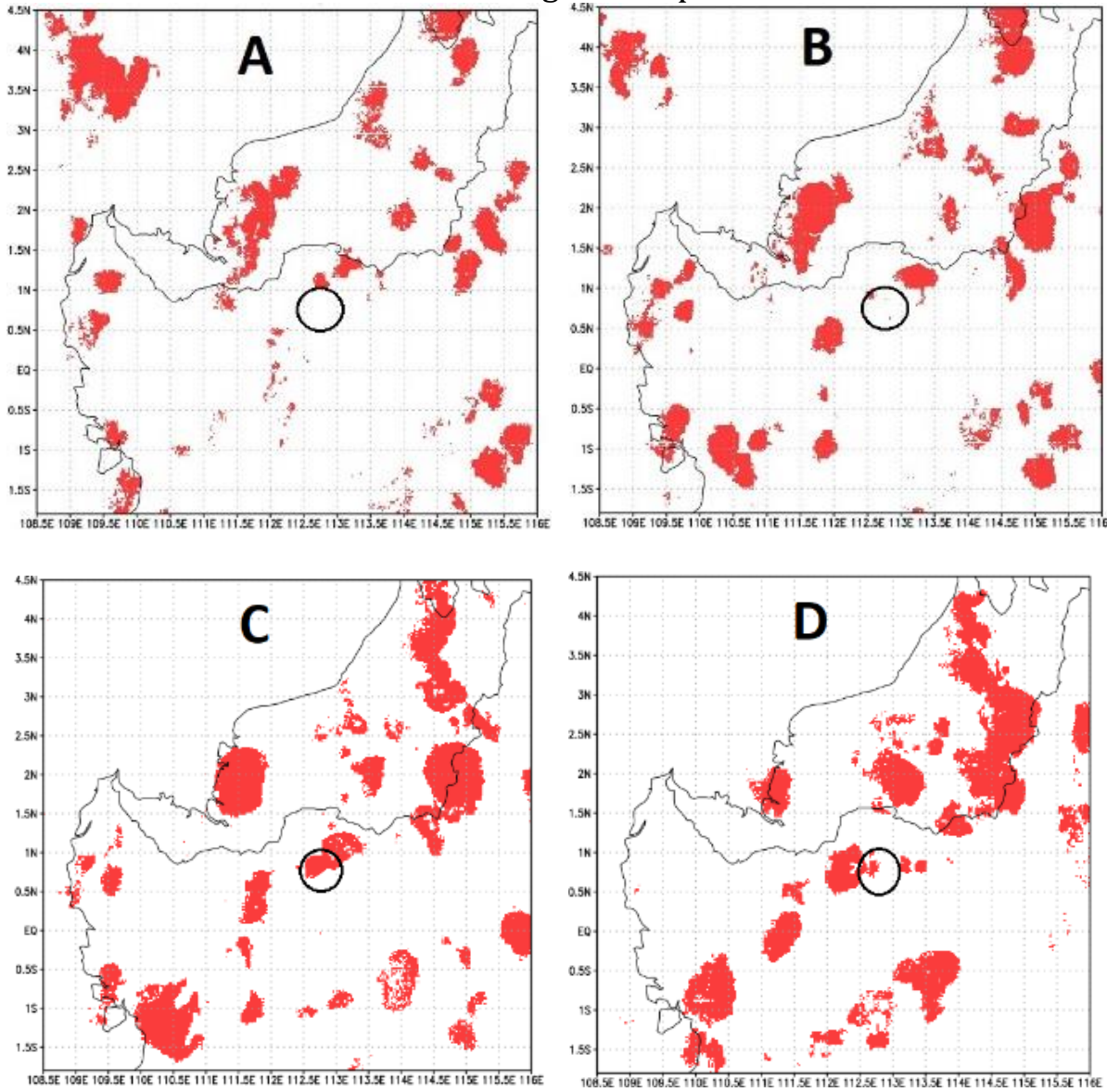

Gambar 5. Sebaran Awan Konvektif pukul 09.00 UTC (a), 10.00 UTC (b), 11.00 UTC (c) dan 12.30 UTC (d) di wilayah Putussibau menggunakan metode CCO

\section{Simpulan}

Metode NM-RGB dan CCO dapat mengidentifikasi sebaran awan konvektif dengan baik. Awan konvektif inilah yang mengakibatkan terjadinya hujan lebat di wilayah Putussibau pada 10 September 2020. Sebaran awan konvektif berada di utara wilayah Putussibau yang kemudian bergerak ke wilayah Putussibau dan menjauhi Putussibau menuju ke Barat. Metode NM-RGB memiliki keunggulan dibandingkan dengan metode CCO karena mampu merepresentasikan perbedaan antara awan konvektif dengan awan lain melalui perbedaan warna yang dihasilkan.

\section{Daftar Pustaka}

[1] R. K. Apriadi, R. T. Januarti, T. Winugroho, S. Yulianto, W. Kurniawan, and I. D. K. K. Widana, "Kajian Risiko Bencana Berdasarkan Jumlah Kejadian dan Dampak Bencana di Indonesia Periode Tahun 2010-2020," PENDIPA J. Sci. Educ., vol. 6, no. 1, pp. 35-40, 2022.

[2] S. Wirjohamidjojo and S. Sugarin, "Praktek Meteorologi Kelautan," Jakarta Badan Meteorol. dan Geofis., 2008.

[3] D. Y. Maisarah and Sugiyarto, "Implementasi Fuzzy Neural Network untuk Peramalan Penjualan Sepeda Motor," J. IIm. Mat., vol. 7, no. 2, pp. 65-72, 2020, doi: 
10.26555/konvergensi.v7i2.19604.

[4] A. Zakir, W. Sulistya, and M. K. Khotimah, "Perspektif Operasional Cuaca Tropis," Pus. Penelit. dan Pengemb. Badan Meteorol. Klimatologi dan Geofis., 2010.

[5] D. C. Siregar, S. Kharisma, B. E. A. Haq, and R. D. Ninggar, "Identifikasi Kejadian Kecelakaan Kapal Berbasis Analisis Faktor Cuaca dan Citra Satelit (Studi Kasus Tanggal 18 Juni 2018 di Danau Toba)," J. Fis. Indones., vol. 23, no. 2, p. 8, 2019, doi: 10.22146/jfi.43775.

[6] K. Bessho et al., "An introduction to Himawari-8/9-Japan's new-generation geostationary meteorological satellites," J. Meteorol. Soc. Japan. Ser. II, vol. 94, no. 2, pp. 151-183, 2016.

[7] M. I. Hastuti and A. Mulsandi, "Pemantauan Sebaran Awan Konvektif Menggunakan Metode Cloud Convective Overlays dan Red Green Blue Convective Storms pada Satelit Himawari-8 ( Studi Kasus : Hujan Ekstrim Bima 21 Desember 2016 ) Monitoring Convective Cloud Dispersion Using Cloud Convective," Semin. Nas. Penginderaan Jauh ke-4 Tahun 2017, vol. 8, pp. 477-483, 2017, [Online]. Available: http://sinasinderaja.lapan.go.id/files/sinasja2017/prosiding/56_PEMANTAUAN SEBARAN AWAN KONVEKTIF MENGGUNAKAN METODE CLOUD CONVECTIVE OVERLAYS DAN RED GREEN BLUE CONVECTIVE STROMS PADA SATELIT HIMAWARI8 (HUJAN EKSTRIM BIMA 21 DES 2016).pdf.

[8] E. Diniyati, D. Q. Syofyan, and A. Mulya, "Pemanfaatan Satelit Himawari-8 dengan Metode NWP dan RGB untuk Menganalisis Kondisi Atmosfer Saat Banjir di Sidoarjo Tanggal 28 Mei," J. Pendidik. dan Ilmu Geogr., vol. 6, no. 1, pp. 1-14, 2021.

[9] F. M. J. Abay, "Analisis Dinamika Atmosfer Dan Distribusi Awan Konvektif Menggunakan Teknik Red Green Blue (RGB) Pada Citra Satelit Himawari-8: Studi Kasus Banjir Jakarta 30 Desember 2019 - 1 Januari 2020," Megasains, vol. 12, no. 1, pp. 34-39, 2021, doi: 10.46824/megasains.v12i1.42.

[10] M. Ryan and K. R. Pratama, "Identifikasi trajektori debu vulkanik letusan gunung gamalama dengan hysplit dan metode rgb pada citra satelit himawari 8," J. Meteorol. Klimatologi dan Geofis., vol. 4, no. 2, pp. 29-34, 2017.

[11] M. D. Syifulllah and S. Nuryanto, "Pemanfaatan Data Satelit GMS Multikanal untuk Informasi Perawanan dalam Rangka Mendukung Kegiatan Teknologi Modifikasi Cuaca," J. Sains dan Teknol. Modif. Cuaca, vol. 17, no. 2, pp. 49-57, 2016.

[12] BMKG, "Prosedur standar operasional pelaksanaan peringatan dini, pelaporan, dan diseminasi informasi cuaca ekstrim," Peraturan Kepala Badan Meteorologi, Klimatologi, dan Geofisika Nomor: Kep. 009 tahun 2010. 2010.

[13] B. I. Abadi and R. Sumiharto, "Klasifikasi Curah Hujan Menggunakan Neuro-Fuzzy System Melalui Citra Radar Cuaca," vol. 11, no. 1, 2021, doi: 10.22146/ijeis.57980.

[14] J. A. I. Paski, A. Sepriando, and D. A. S. Pertiwi, "Pemanfaatan Teknik Rgb Pada Citra Satelit Himawari-8 Untuk Analisis Dinamika Atmosfer Kejadian Banjir Lampung 20 - 21 Februari 2017," J. Meteorol. Klimatologi dan Geofis., vol. 4, no. 3, pp. 8-15, 2019, doi: 10.36754/jmkg.v4i3.48.

[15] M. I. Hastuti and A. Mulsandi, "Pemantauan Sebaran Awan Konvektif Menggunakan Metode Cloud Convective Overlays dan Red Green Blue Convective Storms pada Satelit Himawari-8 (Studi Kasus: Hujan Ekstrim Bima 21 Desember 2016)," in Seminar Nasional Pengindraan Jauh ke-4 Tahun, 2017, pp. 477-483. 